Carlos Ruiz de Alegría Puig ${ }^{1}$

María Macho Díaz ${ }^{2}$

Jesús Agüero Balbin ${ }^{1}$

Jorge Calvo Montes'

\title{
First case of Arcobacter cryaerophilus in paediatric age in Spain
}

'Hospital Universitario Marqués de Valdecilla. Servicio de Microbiología, Spain

${ }^{2}$ Servicio de Pediatría, Atención Primaria, Servicio Cántabro de Salud, Santander, Spain.

Article history

Received: 16 November 2020; Revision Requested: 26 December 2020; Revision Received: 30 December 2020; Accepted: 4 February 2021; Published: 3 April 2021

\section{Sir,}

The genus Arcobacter, a producer of gastroenteritis in humans, is one of the so-called emerging clinical pathogens [1]. It is closely related to the genus Campylobacter and, as it, has been found to be related to the consumption of vegetables, shellfish, milk, water and meat, both beef and pork as well as poultry $[2,3]$. Arcobacter butzleri, Arcobacter cryaerophilus and Arcobacter skirrowii are the most related species to clinical pathology, although in the bibliography the most prevalent is A. butzleri [4]. In Spain A. butzleri, A. cryaerophilus, and A. skirrowii were detected with an overall prevalence close to $40 \%$ and were isolated from (73.3\%) shellfish samples, (55\%) chicken samples, $(42.8 \%)$ fresh cow's milk samples, $(10 \%)$ pork samples, and (5\%) beef sample [5]. Molecular and proteomic methods implemented in clinical microbiology laboratories make it significantly easy to identify, which is also necessary by the greater resistance of the genus than Campylobacter to antibiotics [6]. The ignorance of the low susceptibility to ciprofloxacin, 51\% of the A. cryaerophilus strains tested resistant compared with only $13 \%$ of A. butzleri [7], can make us underestimate the importance of this enteropathogen and fail in treatment in adults. Meanwhile from 25\% to 50\% of the strains of Arcobacter tested in different studies were resistant to macrolides $[7,8]$, which is the usual treatment for diarrhea in Spain for children.

A 12-year-old male who goes to Primary Care consultation referring for two months, coinciding with the confinement derived from the pandemic by COVID-19, liquid bowel movements, in number of 3-4 per day, yellowish, without pathological products; refers to mild intermittent pain prior to emission, without nausea, vomiting or accompanying fever.

Correspondence:

Carlos Ruiz de Alegria Puig

Hospital Universitario Marqués de Valdecilla. Servicio de Microbiologia. Avda. Valdecilla s/n

CP: 39008 Santander, España.

Phone: +34 636322882

E-mail: carlosrdap@hotmail.com
Family does not report any symptomatology in the rest of the cohabitants (parents and brother). The family coexists with a domestic cat in perfect condition; they also do not refer to suspicions of having consumed food or beverages suspected of contamination. It was decided to collect stool sample for coproculture and parasite study, and astringent diet and oral rehydration serum on demand is recommended.

From the microbiology laboratory, the negative examination for parasites and positive growth in Campylobacter medium (CCDA selective medium, Thermo Fisher Diagnostics, Hemel Hempstead, United Kingdom) was reported after two days under microaerophilia conditions at $37^{\circ} \mathrm{C}$. The colonies were identified as $A$. cryaerophilus with a $99.9 \%$ confidence level by MALDI-TOF Vitek-MSTM (v3.2 SARAMIS MS-ID, BioMérieux, Marcy-l'toile, France) and confirmed by sequencing the $16 \mathrm{~S}$ rRNA gene (BlastN; Accession number: NR 025905.1). Gradient strips (Etest) were used to determine susceptibility to antibiotics and resulted resistant to cefazolin, erythromycin, amoxicillin-clavulanic and ciprofloxacin. Intermediate for imipenem and sensitive to tetracycline, doxycycline and gentamicin. When reporting the results, given the persistence of the clinic, treatment with doxycycline $100 \mathrm{mg}$ was indicated every 12 hours for 5 days. Four days after the start of treatment the patient clearly improves, by decreasing in the number of bowel movements and increasing in consistency, and on the 10th day of treatment they were completely normalized. Samples were collected for coproculture in the cohabitants and rectal smears in the pet, resulting in negative both coprocultures, parasite study as well as immunochromatography for enteropathogen viruses. In the pet, also, was not identify A. cryaerophilus in the rectal smears.

This clinical case serves to alert pediatricians and gastroenterologists to the appearance of this genus of emerging enteropathogens, in which the usual empirical treatment, such as the prescription of quinolones or macrolides, may have no effect, proposing the use of tetracyclines for the treatment of this infection. We would also advise microbiologists not to 
incubate Campylobacter plates at $42^{\circ} \mathrm{C}$ but at $37^{\circ} \mathrm{C}$, or better between 25 and $30^{\circ} \mathrm{C}$ since this type of enteropathogens are not thermophilic adapting in this way the protocols of clinical microbiology laboratories to the identification of this type of emerging enteropathogens. And finally, in the face of a case not related to the rural environment, it would remain to be determined the effect that COVID-19 confinement has had on food in Spain, as well as urging the institutions responsible for public health to take greater control measures on the food industries.

\section{FUNDING}

None to declare.

\section{CONFLICTS OF INTEREST}

The authors declare that they have no conflict of interest.

\section{REFERENCES}

1. Ferreira $S$, Queiroz $J A$, Oleastro $M$, Domingues FC. Insights in the pathogenesis and resistance of Arcobacter: A review. Crit Rev Microbiol. 2016;42:364-83. doi: 10.3109/1040841X.2014.954523.

2. Shange N, Gouws P, Hoffman LC. Campylobacter and Arcobacter species in food-producing animals: prevalence at primary production and during slaughter. World J Microbiol Biotechnol. 2019;35:146. doi: 10.1007/s11274-019-2722-x.

3. Mottola A, Bonerba E, Figueras MJ, Pérez-Cataluña A, Marchetti $P$, Serraino $A$, et al. Ocurrence of potentially pathogenic arcobacters in shellfish. Food Microbiol. 2016;57:23-7. doi: 10.1016/j. fm.2015.12.010.

4. Vandenberg O, Dediste A, Houf K, Ibekwem S, Souayah H, Cadranel $\mathrm{S}$, et al. Arcobacter species in humans. Emerg Infect Dis. 2004;10:1863-7. doi: 10.3201/eid1010.040241.

5. Nieva-Echevarria B, Martinez-Malaxetxebarria I, Girbau C, Alonso $R$, Fernández-Astorga $A$. Prevalence and genetic diversity of Arcobacter in food products in the north of Spain. J Food Prot. 2013;76:1447-50. doi: 10.4315/0362-028X.JFP-13-014.

6. Ramees TP, Dhama K, Karthik K, Rathore RS, Kumar A, Saminathan $M$, et al. Arcobacter: an emerging food-borne zoonotic pathogen, its public health concerns and advances in diagnosis and control - a comprehensive review. Vet 0. 2017;37:136-61. doi: 10.1080/01652176.2017.1323355.

7. Van den Abeele AM, Vogelaers D, Vanlaere E, Houf K. Antimicrobial susceptibility testing of Arcobacter butzleri and Arcobacter cryaerophilus strains isolated from Belgian patients. J Antimicrob Chemother. 2016;71:1241-4. doi: 10.1093/jac/dkv483.

8. Fera MT, Maugeri TL, Giannone M, Gugliandolo C, La Camera E, Blandino $G$, et al. In vitro susceptibility of Arcobacter butzleri and Arcobacter cryaerophilus to different antimicrobial agents. Int J Antimicrob Agents. 2003;21:488-91. doi: 10.1016/s09248579(03)00004-9. 